\title{
Estimation of sensible and latent heat based on measurements for non-typical large room
}

\author{
Sylwia Szczęśniak ${ }^{1, *}$, and Juliusz Walaszczyk ${ }^{1}$ \\ ${ }^{1}$ Wroclaw University of Science and Technology, Faculty of Environmental Engineering, \\ ul. Norwida 4/6 50-370 Wroclaw, Poland
}

\begin{abstract}
The knowledge about dynamic changing heating and cooling load in existing building is essential for proper energy management. Whenever existing building is analyzed or ventilation system is going optimized, it's essential to estimate temporary sensible and latent heat based on historical data. The basic conditions for heat calculations are quasi-stable thermal conditions. If supply air temperature significantly varies in short time, what happens very often, the calculations can give untrue results. The procedure described in this article improves usability of measured data affected by rapid supply air temperature changing. Therefore real sensible and latent heat can be calculated, what it is important for future optimization process. Specified, on the basis of varying supply and exhaust air temperatures, thermal loads range from $-55.8 \mathrm{~kW}$ to $40.7 \mathrm{~kW}$ was substitute to more authentic range from $-14.1 \mathrm{~kW}$ to $51.2 \mathrm{~kW}$ received from the conducted simulations. In addition, the data obtained from the simulation showed that latent heat gains were associated with the air temperature in the room, and not with the operation mode of the ventilation unit (day/night) as observed on the basis of historical data.
\end{abstract}

\section{Introduction}

Currently, people spend over $90 \%$ of their time inside buildings. Such a long time spent inside the rooms became the reason for strengthening the role of internal comfort conditions for health, work efficiency, productivity and satisfaction of their users [1]. The constant increase in comfort requirements including thermal comfort in the rooms has been and continues to be the reason for the increase in energy demand needed to ensure this. At the same time, in the era of climate change and global warming, sustainable use of energy is extremely important. Almost one third of the global primary energy supply is used for buildings and $40 \%$ of the world's energy is being consumed in buildings ultimately, it accounts for $30 \%$ of the $\mathrm{CO}_{2}$ emissions [1].

Considering both requirements for reducing the energy demand and the indoor air quality, it is concluded that energy savings in buildings is a key point towards more sustainable energy future [2]. Sustainability is defined from a global point of view and it's referred to a green planet [3]. Half of the energy consumed in the European Union is absorbed by heating and cooling systems serving buildings, and unfortunately a very significant part of this energy

* Corresponding author: sylwia.szczesniak@pwr.edu.pl 
is wasted. Therefore, developing a strategy to increase the efficiency of heating and cooling is a priority of the energy union. This strategy should contribute in principle to reduce energy imports and to reduce costs incurred by the enterprise. Strategy focuses on greenhouse gas emissions reduction and fulfillment of the EU commitment adopted under the climate agreement concluded at the Paris Conference on Climate Change (COP21) [4]. It happens that the implementation of plans differs significantly from reality. Very often, the need to reduce costs at the construction stage means that HVAC systems are not properly performed and/or sampled. In new buildings intelligent control systems like Building Control System (BCS) or Building Management System (BMS) are commonly used. These systems, among other functions, have the ability to continuously control,indoor air parameters. On the basis of the algorithms implemented in the systems, programs control the operation of basic heating and cooling devices. In Poland, it is quite rare, but it happens that air conditioning system provides both heating and cooling features. In this case, knowledge about changing heating and cooling loads is essential for proper energy management. The most important parameter decisive for the energy demand for air treatment and transport is the supply and exhaust air flow. Reliable design of HVAC systems in the building should be preceded by simulation of cooling and heating loads. Unfortunately, this is not always possible due to many reasons. However, at the design stage, when all the physical and thermodynamical parameters of buildings and rooms are known, the execution of such simulations, although time-consumption, should always be carried out. This is of key importance, especially with regard to the designed system of air flow through the room, such as, for example stratified air distribution systems (STRAD) [5]. The matter is much different if the heating or cooling load is to be determined for an existing building. The difficulty usually lies in the lack of the ability to measure individual systems or the entire building and detailed information on the thermal properties of the materials used. For existing buildings, there should be procedures to estimate the hourly heating and cooling demand, which can be determined on the basis of monthly energy consumption [6]. This approach, however, is only possible with the correct and individual measurement equipment of individual HVAC systems. In most cases, this is not possible in Poland due to the very high costs of developing automatic control and regulation systems.

The lack of the possibility of extending existing HVAC and BMS systems and the necessity to ensure the required conditions of indoor air quality with the minimized energy demand makes it extremely important to estimate the momentary heating and cooling loads. Knowledge of the actual values of heating and cooling loads can be the basis for comparing different control algorithms that can be used for individual HVAC systems or individual ventilation and air conditioning devices. It can also be the basis for determining the correct parameters of air systems such as supply air temperature [7], changes in the supply and exhaust air flow etc.

\subsection{Research object}

The object, for which the measurements were taken, is located in the Afrykarium building in Wroclaw zoo. The facility is available for the tourists all year round. This research considers a separated zone in the Afrykarium building. The climate conditions characteristic for Congo rainforests must be maintained there. Congo area dimensions are $\mathrm{W} \times \mathrm{L} \mathrm{x} \mathrm{H}=41.5 \times 41.5 \mathrm{x}$ $14.5 \mathrm{~m}$, what gives floor size of $1722 \mathrm{~m}^{2}$, and approximate space of $25000 \mathrm{~m}^{3}$. There are two open water tanks: the first one with the manats $\left(317.5 \mathrm{~m}^{2}\right)$ and the second one with the crocodiles $\left(130 \mathrm{~m}^{2}\right)$. There is approximately $580 \mathrm{~m}^{2}$ floor space dedicated for tourists. Vegetation surface equals $1700 \mathrm{~m}^{2}$. Room space is settled with exotic birds. According to zoologists and botanists requirements, air temperature should be maintained between $22^{\circ} \mathrm{C}$ 
and $33^{\circ} \mathrm{C}$ and relative air humidity should be always above $60 \%$. The required climatic Congo conditions are provided by one ventilation system. This system is built by two supply air handling unit (AHU) and exhaust air handling unit. The outside air can be filtered, precooled or pre-heated in a glycol exchanger for heat recovery, mixed with exhaust air in mixing chamber, heated or cooled. Supply and exhaust fans are responsible for the air flow. Volumetric air flow for two parts of the system is on the same level and equal $45000 \mathrm{~m}^{3} / \mathrm{h}$. In order to determine the actual values of heat/cooling load in the room, the days characteristic for the thermodynamic conditions of the transition period were selected. In this article the measurements from 2 days were used. -*-Measured values came from $15^{\text {th }}$ and $16^{\text {th }}$ of May 2017. All data were saved with 10 minutes time interval.

\subsection{Research background}

Current control algorithm provides 2-step regulation of supply air temperature and 2-step regulation of supply/return airflow. Supply air temperature is constant during day $\left(27^{\circ} \mathrm{C}\right)$ and constant during night $\left(24^{\circ} \mathrm{C}\right)$. Airflow regulation works also in night and day mode with fan control signal respectively $70 \%$ and $100 \%$.

Current control strategy doesn't take into account temporary thermal load. Furthermore, constant supply air temperature can increase heating energy demand in respect of variable supply air temperature. For example in winter, when outdoor temperatures are low, supply air temperature lower than $27^{\circ} \mathrm{C}$ might also guarantee good indoor conditions at lower energy for heating. Such potential should be investigated.

Investigation could examine different control strategies. Current strategy called $" 27^{\circ} \mathrm{C}$ constant supply air temperature" could be compared with other strategies, for example " $26^{\circ} \mathrm{C}$ constant supply air temperature", "constant indoor air temperature", "constant supply air temperature with variable airflow volume", and with many others. These strategies can be verified in simulation experiments at the same values of input data. If measured values will be use as input data, the interesting results can be obtained. As a result energy consumption during 2 days of real operation can be compared to energy consumption during the same time window at optimized control algorithm. Such comparing can be prepared base on static model, when each data sample is time independent (each 10-minutes sample is selfcontained). Static model is simple to use and is popular in practice.

\subsection{Research objectives}

When static model will be use in simulation experiments, it will be necessary to treat real temporary sensible and latent heat as one of model inputs. This article focuses on real thermal load got from measurements and describes how measured values have been converted in order to use them in further research. This preparation was absolutely necessary because sensible and latent heat computed directly from measurements were not credible.

\section{Methodology}

Simple thermal load calculations can conduct to unreliable results. In such situations the dynamic model of real object can help to eliminate disturbances. 


\subsection{Thermal load calculating based on measurements}

In practice sensible heat is often calculated from Eq. (1).

$$
H_{\mathrm{s}}=c_{\mathrm{p}} \rho V\left(T_{\text {ret }}-T_{\text {sup }}\right)
$$

where: $H_{\mathrm{s}}[\mathrm{W}]-$ sensible heat, $c_{\mathrm{p}}[\mathrm{J} /(\mathrm{kg} \mathrm{K})]-$ specific heat of air at constant pressure, $\rho$ $\left[\mathrm{kg} / \mathrm{m}^{3}\right]$ - air density, $V\left[\mathrm{~m}^{3} / \mathrm{s}\right]$ - air volume, $T_{\text {ret }}\left[{ }^{\circ} \mathrm{C}\right]$ - return air temperature, $T_{\text {sup }}\left[{ }^{\circ} \mathrm{C}\right]-$ supply air temperature. Total heat can be calculated based on Eq. (2).

$$
H_{\mathrm{t}}=\rho V\left(h_{\mathrm{r}}-h_{\mathrm{s}}\right)
$$

where: $H_{\mathrm{t}}[\mathrm{W}]$ - total heat, $\rho\left[\mathrm{kg} / \mathrm{m}^{3}\right]$ - air density, $V\left[\mathrm{~m}^{3} / \mathrm{s}\right]$ - air volume, $h_{\mathrm{r}}[\mathrm{J} / \mathrm{kg}]-$ enthalpy of return air, $h_{\mathrm{s}}[\mathrm{J} / \mathrm{kg}]$-enthalpy of supply air. Latent heat $H_{1}$ are often calculated from Eq. (3) which means from total heat $H_{\mathrm{t}}$ subtract sensible heat $H_{\mathrm{s}}$.

$$
H_{\mathrm{l}}=H_{\mathrm{t}}-H_{\mathrm{s}}
$$

In many cases return and supply air parameters indicate thermal load which should be assimilated by ventilation air. This approach is based on assumption that air parameters in return duct approximate air parameters in conditioned space. When this assumption is applicable, sensors can be localized in return duct and control system responds to return air temperature changes. In most cases control system reacts fluently on return air temperature changing and finally supply air temperature is slowly adjusted. Because of relatively minor return/supply air temperature change in short time period, in practical situations whole object is treated as working in inert state. Then sensible and latent heat can be calculated based on Eq. (1-3). Sometimes, in real situations, return/supply air temperature can significantly vary in relatively short time. Then it is hard to say, that object is in inert state. In such situations simple thermal load calculations based on Eq. (1-3) can give inauthentic results.

\subsection{Stabilize object in simulation}

An intensive supply air temperature change lead to return air temperature change, but not so immediately, due to inertia of room. Therefore thermal load calculations are different before temperature step-change and immediately after temperature step-change. For rooms with big inertia, the difference can be much significant. In addition, by the time object return to quasi steady state, the other heat or cooling loads changing can occur. Finally it will hard to theoretically remove supply air disturbance, because it is hard to indicate form which moment the object is in quasi steady state.

One method to remove supply air temperature disturbance is simulation experiment. First step to achieve this is to prepare a real object model. The model response for measured input should be as near as possible to measured output values. For data sample $k$, temperature error $\Delta T_{k}$ between measured return temperature $T^{\prime}(k)$ ret and simulated return temperature $T_{(\mathrm{k}) \text { ret }}$ can be calculated using Eq (4). To compare all model responses during 48 hours period (each model response has $n$ data samples) can be used Root Mean Square Error (RMSE), which is described by Eq. (5).

$$
\Delta T_{k}=\left(T_{(k) r e t}^{\prime}-T_{(k) r e t}\right)
$$




$$
\operatorname{RMSE} \sqrt{\frac{\sum_{k=1}^{n} T_{k}^{2}}{n}}
$$

In the next step the model should be tested for input excitation without air supply disturbance. The model answer can be interpreted as return air temperature at constant supply air temperature. Simulations results can be used for thermal load calculations. These calculations should be more reliable then calculations based on burdened measurements.

\section{Experiments}

\subsection{Thermal load calculating based on measurements}

Sensible and latent heat was calculated based on measurements using Eq. (1-3). Sensible heat chart was placed on Fig. 1 and latent heat chart was shown on Fig. 2.

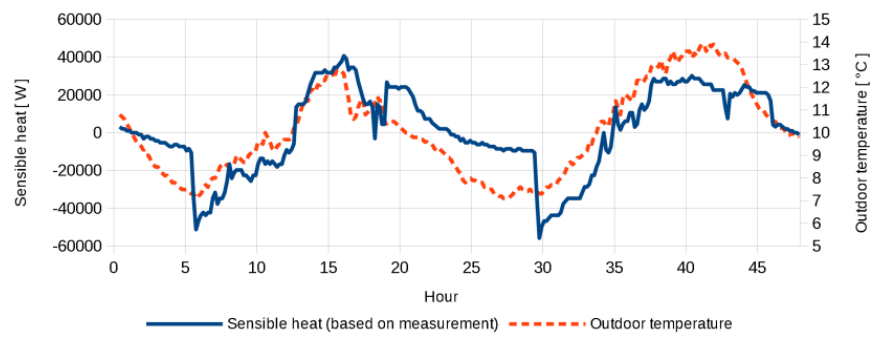

Fig. 1. Sensible heat (based on measurements) against the background of outdoor temperature.

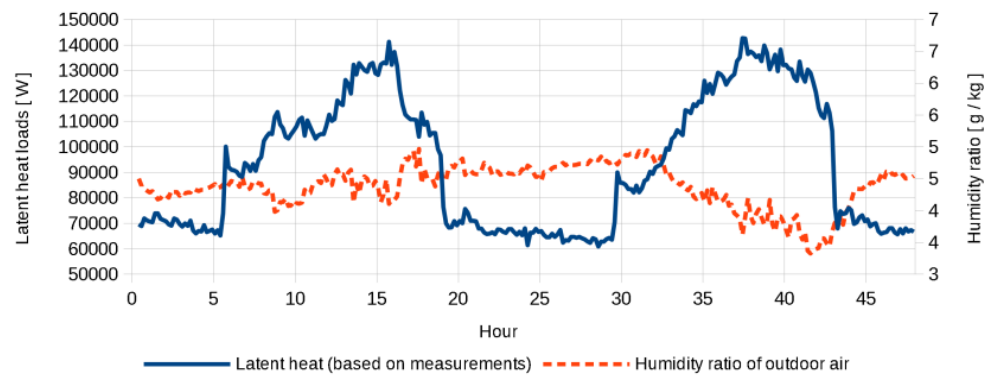

Fig. 2. Latent heat (based on measurements) against the background of outdoor humidity ratio.

On Fig. 1 close to $5^{\text {th }}$ and $30^{\text {th }}$ hour there is a chart collapse. This collapse came not from real thermal load changing, but from step changing supply air parameters. Simultaneously supply air temperature and supply airflow were changed. Low supply air temperature and low airflow were applied during the night mode, and higher values of temperature and airflow were applied during the day mode. Rapid supply air parameters changing made slow change of return air temperature due to inertia of real object. In practice night/day mode switching is responsible for object state, which can't be considered as quasi steady-state. Therefore thermal load obtained from measured data are not reliable. 


\subsection{Preparing the object model}

Object's model was prepared based on time depended first order differential equation. Eq. (4) takes into account ventilation, heat lost through walls, solar radiation and some constant heat gain. Constant parameters of Eq. (4) were found during Nelder-Mead optimization process. Optimization process was executed several times with different start points in order that avoid trap in local minimum.

$$
c_{p} \rho W\left(\mathrm{~d} T_{r} / \mathrm{d} t\right)=c_{p} \rho V\left(T_{\text {sup }}-T_{\text {ret }}\right)+k_{l}\left(T_{\text {out }}-T_{\text {ret }}\right)+P_{\text {const }}+k_{2} S
$$

where: $c_{\mathrm{p}}[\mathrm{J} /(\mathrm{kg} \mathrm{K})]$ - specific heat of air at constant pressure, $\rho\left[\mathrm{kg} / \mathrm{m}^{3}\right]$ - air density, $W\left[\mathrm{~m}^{3}\right]$ - total room volume, $t[\mathrm{~s}]$ - time, $\left(\mathrm{d} T_{r} / d t\right)$ - return air temperature derivative, $V\left[\mathrm{~m}^{3} / \mathrm{s}\right]-$ air volume, $T_{\text {sup }}\left[{ }^{\circ} \mathrm{C}\right]-$ supply air temperature, $T_{\text {ret }}\left[{ }^{\circ} \mathrm{C}\right]-$ return air temperature, $k_{l}$ - constant coefficient, $T_{\text {out }}\left[{ }^{\circ} \mathrm{C}\right]$ - outdoor air temperature, $P_{\text {const }}[\mathrm{W}]$ - constant heat gain, $k_{2}$, - constant coefficient, $S[\%]$ - solar radiation proportional signal.

Model response was the closest to measured return temperature when $k_{1}, k_{2}, P_{\text {const }}$ were near to respectively $11,628,306810$. In this case RMSE of model response came to 0.4894 . Measured return air temperature and model response is shown on Fig. 3. In addition absolute temperature error for each data sample is shown on second axis. Most of data samples $(95 \%)$ fit temperature error from $0{ }^{\circ} \mathrm{C}$ to $0.9^{\circ} \mathrm{C}$.

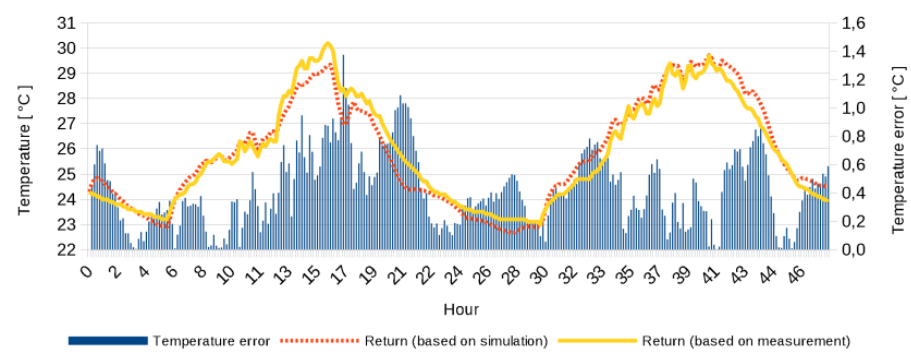

Fig. 3. Measured return air temperature (yellow), simulated return air temperature (red dotted) and absolute temperature error (blue columns, second axis).

\subsection{Estimating real thermal load based on simulation}

The model was tested with constant supply/return airflow and constant supply air temperature. Other input parameters came from measured values. This experiment simulate situation that during 2 days ventilation system works in night mode. Thereby ventilation system doesn't lead object to unsteady state. Using simulation results proper sensible and latent heat were calculated based on Eq. (1-3). Proper sensible heat chart was plotted on Fig. 4 and latent heat chart was shown on Fig. 5.

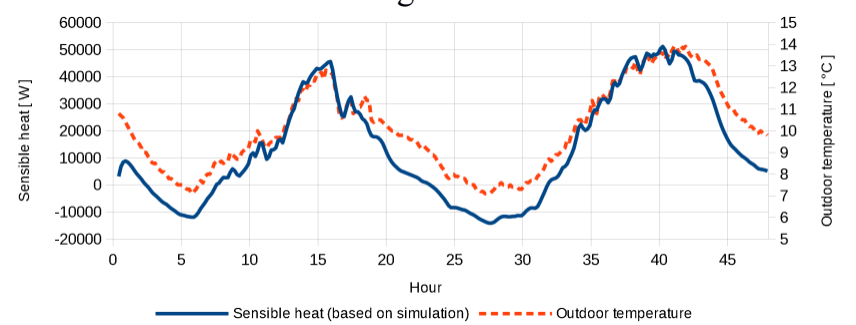

Fig. 4. Sensible heat (based on simulation) against the background of outdoor temperature. 
For better general view, on Fig. 6 several temperatures were showed. Measured supply air temperature (blue line) changed according to night/day mode, but there can observe some fluctuation on the plotted line. Thus AHU plant wasn't maintaining supply air temperature perfectly constant $\left(24^{\circ} \mathrm{C}\right.$ or $\left.27^{\circ} \mathrm{C}\right)$. This issue can also influent for untrue thermal load calculation based on measurements. That was extra argument for simulation experiment.

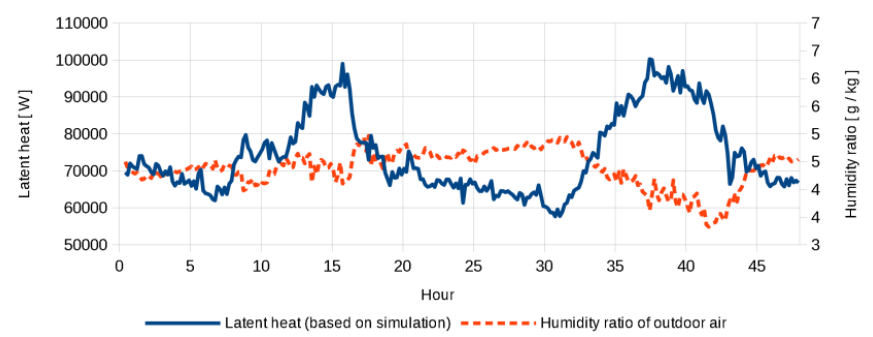

Fig. 5. Latent heat (based on simulation) against the background of outdoor humidity ratio.

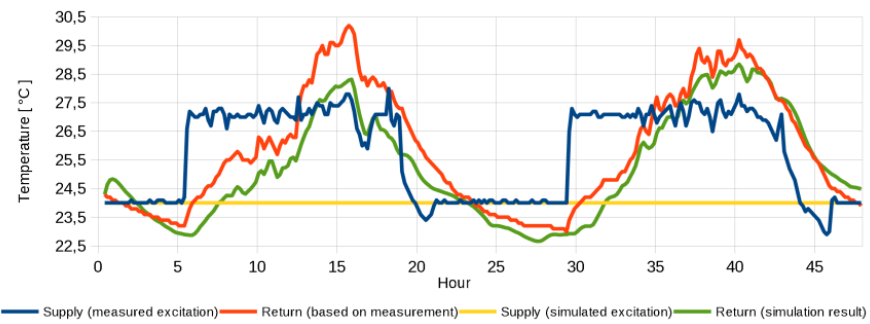

Fig. 6. Several air temperatures for better comparing measurements and simulation.

\section{Discussion}

Sensible heat calculated from measurements (see Fig. 1) were from $-55.8 \mathrm{~kW}$ to $40.7 \mathrm{~kW}$. The biggest drop between 10-minutes neighboring samples is $-24 \mathrm{~kW}$ and the biggest increase is over $22 \mathrm{~kW}$. The most significant drop showed on Fig. 1 between 5:25 and 5:45 is over $40 \mathrm{~kW}$. If chart in Fig. (1) would be reliable, during 20 minutes that would be heat lost over $40 \mathrm{~kW}$. Such heat lost is rather improbably in real situation at observed outdoor conditions and building characteristic. Sensible heat calculated from simulation results (see Fig. 4.) were from $-14.1 \mathrm{~kW}$ to $51.2 \mathrm{~kW}$. The biggest drop between 10 -minutes neighboring samples is $-5.2 \mathrm{~kW}$ and the biggest increase is $4.4 \mathrm{~kW}$. Calculating sensible heat directly from measurements would lead close to 4 times less minimum value $(-55.8 \mathrm{~kW}$ in respect to $-14.1 \mathrm{~kW})$. Maximum value got from measurement was $10 \mathrm{~kW}$ lower then simulation results $(40.7 \mathrm{~kW}$ in respect to $51.2 \mathrm{~kW})$. When currently existed control system switched form night-mode to day-mode, it was rapidly raise supply air temperature from $24^{\circ} \mathrm{C}$ to $27^{\circ} \mathrm{C}$. Return air temperature hasn't to change so fast because the object has big inertia especially due to quite large cubature $\left(25000 \mathrm{~m}^{3}\right)$. In effect thermal load calculation based on measurements was disturbed because of too low return air temperature in respect to high supply air temperature $\left(27^{\circ} \mathrm{C}\right)$. Maximum 10 -minutes differences by sensible heat conduct to conclusion that real object wasn't in quasi steady-state in respect to object in simulation environment. In extreme conditions, sensible heat calculated from measurements changed over $22 \mathrm{~kW}$ within 10-minutes. In simulation results, maximum sensible heat change equaled less than $5.3 \mathrm{~kW}$ within 10-minutes. Thereby simulation experiment provided more stable results, what is important especially for Eq. (1-3), which are proper with object's quasi steady-state assumption. Latent heat calculated from measurements (see Fig. 2.) were from 
$61 \mathrm{~kW}$ to $143 \mathrm{~kW}$. The plotted line rapidly rise up and drop down according to night/day mode switching. Latent heat calculated from simulation results (see Fig. 5.) were from 58 $\mathrm{kW}$ to $100 \mathrm{~kW}$ and relationship between night/day switching mode can be observed. The relationship between return (exhaust) air temperature and night/day mode switching (see Fig. 6.) can be observed as well. Latent heat were higher at higher air temperature. That may come from additional evaporation from the tanks at higher indoor temperature.

\section{Conclusions}

The first order differential equation was useful for real object modelling. Equation consisted only on few factors, particularly ventilation balance, heat lost through walls, constant heat gain and solar radiation. After picking constant three equation parameters, the model copy real object with RMSE close to 0.49 . Most of data samples (95\%) had absolute error below $0.9^{\circ} \mathrm{C}$. The simple dynamic model of real object allows to observe object at different excitation in respect to measured excitation. In this article model helps to estimate real thermal load. Without the model experiment, sensible heat chart has an unexpected collapse due to supply air parameters change. The collapse happened once in each 24 hours of operation, and consisted from $40 \mathrm{~kW}$ heat lost during 20 minutes, even as supply air temperature and airflow increase in the same time. That heat lost was obviously inauthentic. Therefore calculations based on raw measurement weren't usable. The procedure described in this article improves utility of measured data. False sensible heat range from $-55.8 \mathrm{~kW}$ to $40.7 \mathrm{~kW}$ was substitute to more authentic range from $-14.1 \mathrm{~kW}$ to $51.2 \mathrm{~kW}$ due to simulation experiment. In analyzed case, simulation results decrease maximum sensible heat lost value over $75 \%$ and increase maximum sensible heat value over $25 \%$. The values based on measurement suggest that a significant source of latent heat was switching on when day mode was switching on. Mentioned source delivered over $20 \mathrm{~kW}$ latent heat during 10 minutes. However values based on simulation rather suggest relationship between evaporation and indoor temperature. Latent heat source was not observed. Therefore, thanks to simulation experiment some inaccuracies may be avoided in respect to latent heat loads interpretation. Future work should focus on determining the real sensible and latent heat for representative days of the year. This will admit of preparing of HVAC system control algorithms with providing for sustainable energy management.

We would like to thank AQUA SERWIS and Wroclaw ZOO and its employees for making the measurement object available, as well as engagement and assistance both during the measurements and after their completion.

\section{References}

1. P. H. Shaikh, N. B. M. Nor, P. Nallagownden, I. Elamvazuthi, T. Ibrahim, Renew. Sust. Energ. Rev. 34 (2014)

2. M. A. Sayegh, J. Danielewicz, T. Nannou, M. Miniewicz, P. Jadwiszczak, K. Piekarska, H. Johuara, Renew. Sust. Energ. Rev. 68 (2017)

3. M. M. Samaan, O. Farag, M. Khalil, HBRC Journal, 14 (2018)

4. An EU Strategy on Heating and Coolin, Brussels (2016)

5. Y. Cheng, B. Yang, Z. Lin, J. Yang, J. Jia, Z. Du, Energ. Buildings, 165 (2018)

6. G. Pagliarini, S. Rainieri, P. Vocal, Energy and Environment, 25 (2014)

7. F. Engdahl, D. Johansson, Energ. Buildings 36, 3 (2004) 